\title{
An Investigation of the Causes of Maternal Mortality in Zimbabwe
}

\section{Courage Mlambo}

PHD, Department of Economics, University of Fort Hare

Email:mlamboct@gmail.com

\section{Carlowin Chinamo}

Nurse, Ministry of Health,Zimbabwe

Tawanda Zingwe

Department of Industrial Psychology, University of Fort Hare

\section{Doi:10.5901/mjss.2013.v4n14p615}

\section{Abstract}

The aim of this study was to investigate the main causes of maternal mortality in Zimbabwe. Maternal mortality has been recognized as a public health problem in developing countries. Among the developing countries that have been not making progress in reducing maternal death is Zimbabwe. Since 1990 there has been a large and significant increase in maternal mortality in Zimbabwe and this erases any potential gain in maternal survival achieved by safe motherhood programmes during the preceding decade. This shows that there is a need to investigate the causes of maternal death in Zimbabwe so that solutions can be put in place. Efficient services to improve maternal health in Zimbabwe need policies that are informed by reliable and valid data. This study contributes to the accurate assessment of maternal mortality in Zimbabwe. The study investigated the main cause of maternal mortality at Mpilo hospital. The study used interviews to investigate the causes of martenal mortality in Zimbabwe. Findings from the study showed that that haemorrhage causes most of the deaths. Other major causes were abortion, hypertension and sepsis. The study also offers some practical recommendations based on the research findings.

Keyword: Maternal mortality, Millenium development goals, public health, pregnancy, WHO.

\section{Introduction}

Maternal mortality has been recognized as a public health problem in developing countries. Maternal deaths arise from many factors including poor quality care from health services, risks attributable to pregnancy and childbirth. International efforts have been made to sensitise state's health policymakers, so that curbing maternal mortality becomes one of their top priorities. These efforts are evidenced in high level international policy agreements such as the Millenium Development Goals (MDGs). Khan, Woydyla, Say, Gülmezoglu and Van Look (2006) held that the reduction of maternal deaths is a high priority for the international community, especially in view of the increased attention on the Millennium Development Goals. Marternal mortality has been a global health concern and this has been shown by its inclusion in the MGDS. Sub-Saharan Africa has the highest proportion of maternal deaths; it accounts for 56 per cent of global maternal deaths (UNFPA, 2012).

Over the years, there has been a significant decrease in maternal deaths in Sub-Saharan Africa. Statistics from the UN shows that from 1990 to 2010, the annual number of maternal deaths dropped from more than 543,000 to 287,000 - a decline of 47 per cent (UNFPA, 2012). However the UN report warned that "while substantial progress has been achieved in almost all regions, many countries - especially in sub-Saharan Africa - will fail to reach the MDG target of reducing maternal deaths by 75 per cent from 1990 to 2015" (UN, 2012). This shows that greater progress is still needed in significantly reducing maternal deaths.

Among the countries that have been not making progress in reducing maternal death is Zimbabwe. In 2003 Zimbabwe together with Afghanistan, Kenya, Mozambique, Tanzania, and Malawi were among the countries with the highest MMRs of 1000 or greater in the world (AbouZahr, 2003). Maternal mortality remains disturbingly high in Zimbabwe. Since 1990 there has been a large and significant increase in maternal mortality in Zimbabwe and this erases 
any potential gain in maternal survival achieved by safe motherhood programmes during the preceding decade. Statistics have revealed that the number of women dying of pregnancy and childbirth related complications has almost doubled since 1990. No progress has been achieved in reducing maternal death and as a result of this Zimbabwe might fail to reach the Millennium Development Goal (MDG) target of reducing maternal deaths by 75 per cent from 1990 to 2015. Greater progress is, therefore, needed in significantly reducing maternal deaths in Zimbabwe. This study seeks to investigate the causes of maternal deaths and contribute to the accurate assessment of maternal mortality in Zimbabwe.

\section{Trends in Maternal Deaths in Zimbabwe: A Brief Overview}

Gonda (2012) notes that Zimbabwe's Deputy Prime Minister, Ms Khupe, in 2012, stated that the number of women dying during delivery has increased in Zimbabwe from 725 deaths for every 100000 live births to 960 deaths for every 100000 live births. These alarming figures show that Zimbabwe is lagging behind in achieving the Millennium Development Goals of reducing maternal health and child mortality. Despite the government's efforts to create an enabling policy environment for the implementation of various maternal, neonatal and child health programmes, maternal deaths continue to rise. Figure 1 below shows the trends in maternal death between 1990 and 2012.

Figure 1: Maternal death trends in Zimbabwe: 1990-2012

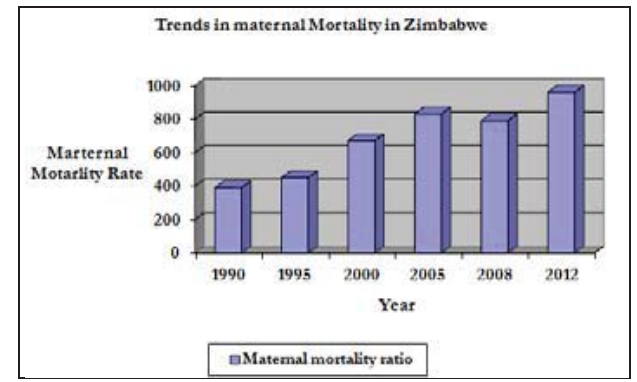

Source: Data compiled from World Bank (2011) and Gonda (2012)

Table shows that maternal mortality remains disturbingly high in Zimbabwe. Maternal mortality was low in the 90s but rose steadily in 1995. It further rose sharply between 1995 and 2000 and it continued with the rising trend until 2005. It then has a slight drop between 2005 and 2008 but it rose again between 2008 and 2012 . From the table, it can be observed that female mortality rates have been worsening since 1990 .

Table 1: Selected Health Indicators for Zimbabwe

\begin{tabular}{|l|c|}
\hline Indicator Name & $\%$ \\
\hline Fertility rate average annual rate of reduction ( & 2 \\
\hline Adolescents aged 15-19 who are currently married/in union (2000-2010*) & 21 \\
\hline Adolescents aged 15-19 who use at least one type of information media at least once a week (2000-2010), female & 60 \\
\hline Skilled attendant at birth (\%) 2006-2010, urban & 86 \\
\hline Skilled attendant at birth (\%) 2006-2010*, rural & 58 \\
\hline
\end{tabular}

Source: Data compiled from UNICEF (2013)

Table 2.1 shows that the fertility rate in Zimbabwe is fairly low; it has been decreasing over the years. The percentage of adolescents aged 15 to 19 who are currently married stands at 21 and this is fairly high. This shows that there is early marriage in Zimbabwe. The table also shows that there is a huge problem in rural areas; the rate of births attendant by a skilled person at birth is very low. This is a huge problem as it contributes significantly to the maternal deaths.

Over the years the government has treated the maternal mortality problem as a national priority. The Ministry of Health (2013) states that the government carried out a comprehensive Maternal Neonatal Health (MNH) Assessment whose findings formed the basis for the MNH Road Map (2007-2015). Policies have been developed to curb the high maternal mortality rate and there have been relentless efforts to increase skilled birth attendance. "Confronted with the worsening "brain drain" of general nurses and midwives, the Ministry introduced a new generic cadre, the Primary Care Nurse. These nurses are trained specifically to function at primary health care level (Ministry of Health, 2013). All these 
efforts have been meant to reduce maternal deaths but the maternal deaths continue to rise significantly. Maternal mortality, therefore, remains a pressing to the government of Zimbabwe and as a result of this, there is need for this area to be investigated and this is the aim of this study.

\section{Literature Review}

This section surveys literature that sought to investigate the causes of maternal deaths in developing countries and in Zimbabwe. The fact that maternal deaths matter and are a global concern has compelled researchers to investigate the factors that lead to increases in maternal deaths.

\subsection{Literature from developing countries}

Fauveau et al (1988) conducted a study on the causes of maternal mortality in rural Bangladesh between 1976 and 1985. Major causes of maternal death, which were assessed using a combination of record review and field interviews, included postpartum haemorrhage (20\%), complications of abortion (18\%), eclampsia (12\%), violence and injuries (9\%), concomitant medical causes (9\%), postpartum sepsis (7\%), and obstructed labour $(6.5 \%)$. Deaths caused by postpartum haemorrhage were positively associated with both maternal age and parity, whereas those caused by eclampsia and injuries were more common among young and low-parity women.

Hoestermann, Ogbaselassie, Wacker and Bastert (1996) investigated the causes of maternal mortality in the main referral hospital in The Gambia in West Africa. An analysis of maternal deaths was done at the maternity unit of the main tertiary level hospital in The Gambia. Findings from the study revealed that the major cause of maternal deaths was haemorrhage (24\%), followed by hypertensive disorders in pregnancy and Sepsis was third. Results also showed that anaemia led among the indirect causes of death.

Kodio et al (2002) investigated the causes of maternal mortality in Senegal. They used a questionnaire to obtain information from relatives of the deceased women who died when giving birth. Results showed that haemorrhage was the most common cause of deaths and two-thirds of the maternal deaths were from direct obstetric causes. In another study, Bartlett et al (2005) examined the numbers, causes of maternal deaths among women in Afghanistan. They did a retrospective cohort study of women of reproductive age (15-49 years). The results indicated that martenal mortality was caused by ante-partum haemorrhage. However in Ragh a greater proportion of women died of obstructed labour.

Ujah, Aisien, Mutihi, Vanderjag, Glew and Uguru (2005) assessed the factors contributing to Maternal Mortality in North-Central Nigeria. Data collected was analysed for socio-biological variables including age, booking status, educational level, parity, ethnic group, marital status, mode of delivery, duration of hospital stay before death occurred, cause (s) of maternal deaths. The findings of the study showed that the major direct causes of deaths were haemorrhage (34.6\%), sepsis (28.3\%), eclampsia (23.6\%) and unsafe abortion (9.6\%). The most common indirect causes of death were hepatitis $(18.6 \%)$, anaesthetic death $(14.6 \%)$, anaemia in pregnancy $(14.6 \%)$, meningitis $(12.0 \%)$, HIVIAIDS $(10.6 \%)$ and acute renal failure (8.0\%). Seventy- nine percent of the maternal deaths occurred within 24 hours of admission. However, most of the deaths were preventable.

Khan et al (2006) analysed the causes of maternal death in Africa, Asia, Latin America and the Caribbean. Haemorrhage was seen to be the leading cause of death in Africa and in Asia. On the other hand, hypertensive disorders caused much of the deaths in Latin America and the Caribbean. Resultantly, the study concluded that haemorrhage and hypertensive disorders are leading causes of maternal deaths in developing countries.

Elsewhere, Elhassan, Mirghani and Adam (2009) examined the causes of maternal deaths and stillbirths at Wad Medani, Sudan. Their study covered the period between from 2003 and 2007. All maternal deaths and stillbirths during this period were reviewed and classified retrospectively. The resuls showed that septicaemia was the most common cause of the maternal deaths followed by obstructed labour or abortion-related sepsis, viral hepatitis, haemorrhage, preeclampsia/ecalampsia, and malaria. In another study, Gaym (2009) assessed the different causes of maternal deaths in Ethiopia. The study used electronic databases, interviews and a structured questionnaire to extract relevant data. In addition to this, the study also surveyed Twelve maternal mortality studies were identified from 1980 to 2008. The study found out five major causes of maternal deaths and these were puerperal sepsis, abortion complications, postpartum hemorrhage, ruptured uterus and eclampsia.

EL-Gharib, Rakha, Awara, Alhawari and Mahfouz (2010) assessed the aetiology, trends and causes of maternal mortality (MM) in Tanta University Hospital. They consulted files for each case of maternal mortality fro the period between 2007 and 2009. Their analysis revealed that the main cause of maternal deaths were postpartum haemorrhage, 
caesarean section, preeclampsia/eclampsia, sepsis and embolic phenomena. Makinga et al (2012) conducted a study in South Africa with the objective of determining the clinical and demographic profile of maternal deaths and also to determine the most common primary causes of maternal deaths at district hospital level. The findings from the study indicated that the five leading causes of deaths were non-pregnancy-related sepsis, miscarriage, acute collapse, pregnancy-related sepsis and anaesthetic complications. Thirty patients (49.3\%) received substandard care.

\subsection{Literature from Zimbabwe}

De Muylder (1990) argued that a maternal mortality audit was introduced in the Midlands Province (Zimbabwe) in order to identify which avoidable factors were involved most frequently. During the two-year study period, the maternal mortality rate was 137 per 100,000 total births. The main causes of death were uterine rupture, eclampsia, haemorrhage and caesarean section related accidents. An avoidable factor was identified among $87 \%$ of these deaths involving the health system in $57 \%$ of the cases and the patient in $33 \%$. Access to the health facilities and transport problems only played a minor role.

Mbizvo, Fawcus , Lindmark , Nyström (1993) conducted a community-based incidence case-referent study in in Zimbabwe in an effort to identify factors that were associated with maternal deaths. In the rural setting, haemorrhage, sepsis and abortion were the leading and direct causes of maternal deaths while malaria was the leading indirect cause in the rural setting. Eclampsia, abortion and puerperal sepsis were the leading causes of maternal deaths in the urban setting. The study also shoed that situations associated absent of social support, for example being single, divorced, oe being widowed, carried an increased risk for maternal mortality, especially in the rural area. .

Bicego, Boerma and Ronsmans (2002) examined the effect of AIDS on maternal mortality in Malawi and Zimbabwe. The findings of their study indicated that pregnancy-related mortality risks have increased 1.9 and 2.5 times, respectively, during the past decade, concomitant with a nearly 10-fold increase in the prevalence of HIV among pregnant women. The increase was more pronounced in urban populations.

\subsection{A Brief Assessment of Empirical Literature}

An analysis of empirical literature was done. Empirical literature investigated by the study showed that, in developing countries, most maternal deaths were caused haemorrhage. Most of the studies showed that haemorrhage has been a leading cause of maternal deaths. Other contributing factors to maternal deaths has been unsafe abortion, sepsis, eclampsia, obstructed labour and other causes caused by lack of medical equipment such as ambulances and also lack of qualified staff. Different studies variously found these factors as the leading factors that cause maternal deaths.

\section{Methodology}

In order to effectively carry out the research, this study chose the convenient sampling method. The method was chosen as it involves those who are convenient to the researcher that is subjects who are readily available. In this study subjects were involved for participation in maternity wards. The study population includes women aged between 16 and 35 years. The sample comprises of female aged 16 to 35 years who died due to pregnant related complications in Mpilo Maternity ward between 2011 and 2012. The data were collected through interviews. The researchers conducted 20 interviews with midwives, nurses and health information officers at Mpilo Hospital in Bulawayo. Participation was voluntary and respondents were asked, as part of obtaining informed consent, if they were willing to have their answers recorded.

\subsection{Presentation of Results}

The main results of the study are displayed in table 2 below.

Table 2: Presentation of Results; causes of maternal deaths

\begin{tabular}{|l|c|}
\hline \multicolumn{1}{|c|}{ Diagnoses } & Number of Deaths \\
\hline Haemorrhage & 13 \\
\hline Hypertension & 7 \\
\hline Pneperal Sepsis & 5 \\
\hline Obstetric embolism & 2 \\
\hline Abortion & 10 \\
\hline
\end{tabular}


$n=43$

\begin{tabular}{|l|c|}
\hline Other indirect causes & 6 \\
\hline Total & 43 \\
\hline
\end{tabular}

As shown in table 2 haemorrhage is the highest cause of maternal deaths with cases a total number of 13. Abortion was the second highest cause of maternal deaths; it recorded 10 cases. Hypertension recorded 7 cases of maternal deaths, sepsis recorded 5 cases and other indirect causes recorded 6 cases.

Table 3: Presentation of Results; Number of maternal deaths by age

\begin{tabular}{|c|c|}
\hline Age & Number of Deaths \\
\hline $16-20$ & 14 \\
\hline $21-25$ & 8 \\
\hline $26-30$ & 10 \\
\hline $31-35$ & 11 \\
\hline Total & 43 \\
\hline
\end{tabular}

$n=43$

As shown on table 3, women aged between 16 and 20 years had the highest rate of maternal deaths recording 14 cases. Women aged 21 and 25 years had the lowest rate of maternal deaths. Women aged between 26 and 30 and women aged between 31 and 35 recorded 10 and 11 cases of maternal deaths respectively.

Table 4: Presentation of Results; Maternal deaths by education level

\begin{tabular}{|l|c|}
\hline \multicolumn{1}{|c|}{ Level of Education } & Number \\
\hline Never been to school & 15 \\
\hline Primary & 11 \\
\hline Ordinary level ('O' Level) & 6 \\
\hline Advanced level ('A Level) & 2 \\
\hline Tertiary Level & 9 \\
\hline Total & 43 \\
\hline
\end{tabular}

$n=43$

Table 4 shows that women who had never been to school recorded the highest of maternal deaths. Women who did not proceed with education after their primary education had the second highest maternal mortality rate recording 11 cases of maternal deaths. Women who reached ordinary level recorded 6 cases of maternal deaths, women who reached Advanced level recorded 2 cases and those who reached tertiary level recorded 9 cases of maternal deaths.

\section{Conclusion and Policy Recommendations}

The main objective of his study was to investigate the causes of maternal deaths in Zimbabwe. In this study it was realized that haemorrhage causes most of the deaths. Other major causes were abortion, hypertension and sepsis. The findings of the study also revealed that the 16 and 20 year age group had the highest number of maternal deaths. This is partly explained by the fact that this age group is the one that normally has unwanted pregnancies and as such women from this age group are tempted to do abortion and die in the process. The results showed that those who have never been to school had a higher proportion of being victims of maternal deaths than those who went to school.

Based on its major findings, this study wishes to recommend that for Zimbabwe to reduce maternal deaths and achieve the Millenium Development goal it has to develop and sustain its maternal health capacity. It can do so by implementing the following recommendations: First, given the circumstances that the Zimbabwean government is currently faced with, the Zimbabwean government should seek for financial aid from the international community. Increased funds for training and equipment would also increase the availability of surgical repair of complications associated with maternal deaths.

Second, the Zimbabwean government should ensure that there is the availability of drugs to help prevent haemorrhage as it is a main cause of maternal deaths. Drugs like oxytocin and ergometrine help the womb (uterus) to shrink after a woman has given birth and this helps to prevent heavy bleeding. However, due to high costs of pharmaceuticals developing countries like Zimbabwe cannot afford this. The unavailability of cheap drugs has been a 
pressing challenge for resource-poor settings in developing countries like Zimbabwe. This also shows the need for international assistance and co-operation.

Third, the government should give incentives to health providers to motivate them to do their job effectively. Zimbabwe has qualified nurses but the problem has been incapacity to pay health personnel. There is also need for state to improve motivation of its personnel. Low salaries have resulted in health personnel being demotivated and this has serious implications to pregnant women.

Fourth, Hospitals and birth centre should be properly supported and equipped. Health centres and clinics must have surgical supplies to handle complications. Health facilities do not have the necessary supplies and equipment to take care of woman giving birth. Caring for women with haemorrhage is often beyond the capacity of developing country health systems and communities, since medication used for standard treatment requires refrigeration and injection.

Last but not least, the government must also come up with strong maternal policies. National policies need to support training and deployment of skilled personnel, especially in rural and under-served areas. They must ensure that every pregnant woman registers for delivery and they must also allocate a center where she will give birth. Antenatal visits must be made compulsory and these visits should give health workers the chance to educate women about the importance of safe delivery with a skilled birth attendant, the warning signs of complications, and how to plan for emergency care.

\section{References}

AbouZahr, C. (2003). Global burden of maternal death and disability. Oxford Journals, 67, 1-11

Bartlett, L.A., Mawji S., Whitehead, S., Crouse, C., Dalil, S., Ionete, D., \& Salama, P. (2005), Where giving birth is a forecast of death: maternal mortality in four districts of Afghanistan, 1999-2002. [Online] Available: http://www.ncbi.nlm.nih.gov/pubmed/15752530 (February 25, 2013)

Bicego, G., Boerma, J.T, \& Ronsmans, C. (2002), The effect of AIDS on maternal mortality in Malawi and Zimbabwe. [Online] Available: http://www.ncbi.nlm.nih.gov/pubmed/11953479 ( March 3, 2013)

De Muylder, X. (1990), Maternal mortality audit in a Zimbabwean province. [Online] Available: http://www.ncbi.nlm.nih.gov/pubmed /2369151 (March 3 , 2013)

El-Gharib, M.N., Rakha, S.F., Awara, A.M., Mahfouz, A.F \& Elhawary, T.S. (2010), Causes of Maternal Deaths in Tanta University Hospital. Clinical Medicine Reviews in Women's Health. [Online] Available: www.la-press.com/redirect_file.php?...Causes-of-Maternal-Deaths (Februay 24, 2013)

Elhassan, E.M., Mirghani, O.A., \& Adam, I. (2009), High maternal mortality and stillbirth in the Wad Medani Hospital, Central Sudan, 2003-2007. [Online] Available: http://www.ncbi.nlm.nih.gov/pubmed/19762581 (March 14, 2013)

Fauveau, V., Koenig, M. A., Chakraborty, J. \& Chowdhu, A. I. (1988), Causes of maternal mortality in rural Bangladesh between 1976 and 1985. [Online] Available: http://www.ncbi.nlm.nih.gov/pmc/articles/PMC2491193/ (March 18, 2013).

Fawcus, S., Mbizvo, M., Lindmark, G., and Nyström, L. (1996), A community-based investigation of avoidable factors for maternal mortality in Zimbabwe. [Online] Available: http://www.jstor.org/stable/2138027 (March 18, 2013)

Gaym, A. (2009), Maternal mortality studies in Ethiopia--magnitude, causes and trends. [Online] Available: http://www.ncbi.nlm.nih.gov/pubmed/19743789 (February 27, 2013)

Gonda, V. (2012), Maternal Deaths Surge in Zimbabwe; Deputy Prime Minister Urges Action. [Online]. Available: http://m.voazimbabwe.com la/1470263.html (May 23, 2013)

Hoestermann, C.F., Ogbaselassie, G., Wacker, J., \& Bastert, G. (1996), Maternal mortality in the main referral hospital in The Gambia, West Africa. [Online] Available: http://www.ncbi.nlm.nih.gov/pubmed/8911458 (May 7, 2013)

Khan, K.S, Wojdyla, D., Say,L., Gülmezoglu, A.M, \&Van Look, P.F.A. (2006), WHO analysis of causes of maternal death: a systematic review. [Online] Available: https://centre.icddrb.org/images/WHO_Analysis_of_Causes_of_Maternal_Death_-_Khan_\&_co..pdf (May 7, 2013)

Kodio, B., de Bernis, L., Ba, M., Ronsmans, C., Pison, G., \& Etard, J.F. (2002), Levels and causes of maternal mortality in Senegal. [Online] Available: http://www.ncbi.nlm.nih.gov/pubmed/12031071 (May 7, 2013)

Makinga, P.N, Moodley, J., \& Titus, M.J. (2012), The profile of maternal deaths in a district hospital: a five-year review of maternal deaths from 2006-2010. [Online] Available: www.ajol.info/index.php/safp/article/download/84137/74139 (March 13, 2013).

Mbizvo, M.T., Fawcus, S., Lindmark, G., \& Nyström, L. (1993), Maternal mortality in rural and urban Zimbabwe: social and reproductive factors in an incident case-referent study. [Online] Available: http://www.ncbi.nlm.nih.gov/pubmed/8511649 (March 13, 2013)

Ministry of Health and Child Welfare. (2013), Maternal and Child Health. [Online] Available http://www.mohcw.gov.zw /index.php/reproductive-health (February 17, 2013).

Ujah, I.A.O., Aisien, O.A., Muthir, JT., Vanderjagt, D.J., Glewnand, R.H \& Uguru, V.E. (2005). Factors Contributing to Maternal Mortality in North-Central Nigeria: A Seventeen-year Review. African Journal of Reproductive Health, 9, 27-40.

UN. (2012), Maternal deaths continue to decline but more progress needed - UN report. [Online] Available: http://www.un.org/apps Inews/story.asp?NewsID=42013 (March 18, 2013).

UNFPA. (2012), Sub-Saharan Africa's maternal death rate down 41 per cent. [Online] Available: http://esaro.unfpa.org /public/public/cache/offonce/news/pid/10767 (March 20, 2013).

UNFPA. (2012), Maternal deaths halved in 20 years but faster progress needed. [Online] Available: http://www.unfpa.org /public/home/news/pid/10730 (March 20, 2013).

UNICEF. (2013), Zimbabwe; statistics. [Online] Available: http://www.unicef.org/infobycountry/zimbabwe_statistics.html (May 12, 2013)

WHO. (2012), New UN Report: Maternal deaths nearly halved in 20 years. [Online] Available http://www.who.int /pmnch/media/news/2012/20120516_unfpa_report/en/ (May 12, 2013)

World Bank. (2011), Mortality rate, infant (per 1,000 live births). [Online] Available: http://data.worldbank.org/country/zimbabwe (March 5, 2013) 